\title{
In Vivo Proliferative Regeneration of Balance Hair Cells in Newborn Mice
}

\author{
Joseph C. Burns, ${ }^{1,2 \star}$ Brandon C. Cox ${ }^{4 \star}$ Benjamin R. Thiede, ${ }^{1}$ Jian Zuo, ${ }^{4}$ and Jeffrey T. Corwin ${ }^{1,3}$ \\ Departments of ${ }^{1}$ Neuroscience, ${ }^{2}$ Biomedical Engineering, and ${ }^{3}$ Cell Biology, University of Virginia School of Medicine Charlottesville, Virginia 22908 , and \\ ${ }^{4}$ Department of Developmental Neurobiology, St. Jude Children's Research Hospital, Memphis, Tennessee 38105
}

The regeneration of mechanoreceptive hair cells occurs throughout life in non-mammalian vertebrates and allows them to recover from hearing and balance deficits that affect humans and other mammals permanently. The irreversibility of comparable deficits in mammals remains unexplained, but often has been attributed to steep embryonic declines in cellular production. However, recent results suggest that gravity-sensing hair cells in murine utricles may increase in number during neonatal development, raising the possibility that young mice might retain sufficient cellular plasticity for mitotic hair cell regeneration. To test for this we used neomycin to kill hair cells in utricles cultured from mice of different ages and found that proliferation increased tenfold in damaged utricles from the youngest neonates. To kill hair cells in vivo, we generated a novel mouse model that uses an inducible, hair cell-specific CreER allele to drive expression of diphtheria toxin fragment A (DTA). In newborns, induction of DTA expression killed hair cells and resulted in significant, mitotic hair cell replacement in vivo, which occurred days after the normal cessation of developmental mitoses that produce hair cells. DTA expression induced in 5-d-old mice also caused hair cell loss, but no longer evoked mitotic hair cell replacement. These findings show that regeneration limits arise in vivo during the postnatal period when the mammalian balance epithelium's supporting cells differentiate unique cytological characteristics and lose plasticity, and they support the notion that the differentiation of those cells may directly inhibit regeneration or eliminate an essential, but as yet unidentified pool of stem cells.

\section{Introduction}

In many non-mammalian vertebrates, continuous proliferation of glial and sustentacular stem cells gives rise to new neurons and sensory cells and is paralleled by life-long regeneration (Zupanc, 2008). Such is the case in fish, amphibians, reptiles, and birds, where mechanoreceptive hair cells are produced throughout life and can be regenerated from supporting cells to restore lost hearing, balance, and lateral line functions (Corwin, 1981, 1985, 1986; Corwin and Cotanche, 1988; Jorgensen and Mathiesen, 1988; Ryals and Rubel, 1988; Popper and Hoxter, 1990; Lanford et al., 1996; Warchol, 2011). In those species, hair cell death leads to robust proliferation of supporting cells, whose progeny give rise to replacement hair cells that become innervated and restore sensory functions within weeks. Also, supporting cells sometimes replace lost hair cells by converting directly into a hair cell phe-

Received Dec. 17, 2011; revised March 14, 2012; accepted March 21, 2012.

Author contributions: J.C.B., B.C.C., J.Z., and J.T.C. designed research; J.C.B., B.C.C., and B.R.T. performed research; J.C.B., B.C.C., B.R.T., J.Z., and J.T.C. analyzed data; J.C.B., B.C.C., J.Z., and J.T.C. wrote the paper.

This work was supported in part by grants from the National Institutes of Health DC000200 (J.T.C.), DC006471 (J.Z.), DC008800 (J.Z.), DC010519 (J.C.B.), DC010310 (B.C.C.) and CA21765, the Lions of Virginia Hearing Research Foundation (J.T.C.), the Office of Naval Research (N000140911014), and the American Lebanese Syrian Associated Charities (ALSAC) of St. Jude Children's Research Hospital. J.Z. is a recipient of The Hartwell Individual Biomedical Research Award. We thank S. Baker (St. Jude) for Atoh1-CreER TM mice; J. Bartles (Northwestern University) for the espin antibody; and K. Lee, S. Zeitlin, J. Shin, and M. Rollag (University of Virginia) for discussion and critical comments.

*J.C.B. and B.C.C. contributed equally to this work.

Correspondence should be addressed to Jeffrey T. Corwin, Department of Neuroscience, University of Virginia Medical School, 409 Lane Road, Charlottesville, VA 22908. E-mail: jtc2k@virginia.edu.

DOI:10.1523/JNEUROSCI.6274-11.2012

Copyright $\odot 2012$ the authors $\quad 0270-6474 / 12 / 326570-08 \$ 15.00 / 0$ notype without passing through S-phase (Stone and Cotanche, 2007; Collado et al., 2011b; Lin et al., 2011).

Proliferative or "mitotic" hair cell regeneration appears to be the dominant process responsible for the recovery of hearing, balance, and lateral line sensitivity following hair cell losses in many non-mammals. The irreversibility of similar deficits in mammals has been ascribed to sharp, embryonic declines in the cellular production capacity of inner ear sensory epithelia that were measured through pulse labeling (Ruben, 1967). It remains unclear, however, exactly what restricts regeneration in mammalian ears and what relative contributions proliferative and nonproliferative forms of regeneration make to the limited repair processes that have been observed in balance epithelia from humans and other mammals (Forge et al., 1993, 1998; Warchol et al., 1993; Li et al., 1995; Tanyeri et al., 1995; Kuntz and Oesterle, 1998; Ogata et al., 1999; Oesterle et al., 2003; Kawamoto et al., 2009; Lin et al., 2011). In addition, recent estimates based on cell density measures suggest that hair cell numbers increase during neonatal maturation of murine utricles (Kirkegaard and Nyengaard, 2005). These findings point to the possibility that an unrecognized period of neonatal plasticity might allow murine vestibular organs to repair hair cell losses through significant mitotic regeneration.

To investigate this, we used neomycin to kill hair cells in utricles cultured from young mice, and measured large proliferative responses that declined with age. Although substantial numbers of cells were labeled with BrdU in the youngest utricles, none differentiated into new hair cells under our culture conditions. Therefore, to circumvent limitations of in vitro experi- 
ments, we generated mice that carried a hair-cell-specific CreER allele that allows inducible expression of diphtheria toxin fragment A (DTA). Inducing DTA expression soon after birth killed hair cells and resulted in significant mitotic hair cell replacement in the utricle in vivo, but the response decreased significantly when hair cell death was induced in 5-d-old mice. These findings show that neonatal rodent balance organs possess the machinery for significant mitotic hair cell regeneration in vivo, but regeneration becomes impaired or inhibited later during the time when maturing mammalian supporting cells differentiate characteristics not found in their non-mammalian counterparts.

\section{Materials and Methods}

Animal models. Animal work was approved by the Animal Care and Use Committees of the University of Virginia and St. Jude Children's Research Hospital. Swiss Webster mice were obtained from Charles River. ROSA2 $6^{\text {DTA }}$ mice (stock \#6331) and ROSA26 ${ }^{\text {eYFP }}$ mice (stock \# 6148) were purchased from The Jackson Laboratory. Atoh1-CreER ${ }^{\mathrm{TM}}$ mice were provided by S. Baker at St. Jude Children's Research Hospital (Chow et al., 2006). Mice of either sex were injected with tamoxifen (3 $\mathrm{mg} / 40$ g, i.p.; Sigma-Aldrich) and 5-ethynyl-2-deoxyuridine (EdU; 10 $\mu \mathrm{g} / \mathrm{g}$, i.p.; Invitrogen) at the ages indicated.

Dissection and culture of utricles. Labyrinths were dissected from temporal bones in ice-cold DMEM/F-12 (Invitrogen), the utricles were isolated, and the roof, otoconia, and nerve were mechanically removed under aseptic conditions. The dissected organs contained the entire sensory epithelium, a small portion of the surrounding nonsensory epithelium, and the underlying connective tissue matrix. For organ culture, dissected utricles were adhered to glass-bottom dishes (Mat-Tek) coated with Cell-Tak (BD Biosciences) as described previously (Meyers and Corwin, 2007) and cultured in DMEM/F12 with 1\% FBS (Invitrogen), 3 $\mu \mathrm{g} / \mathrm{ml}$ 5-bromo-2-deoxyuridine (BrdU; Sigma-Aldrich), $0.25 \mu \mathrm{g} / \mathrm{ml}$ Fungizone (Invitrogen), and $10 \mu \mathrm{g} / \mathrm{ml}$ ciprofloxacin (Bayer) at $37^{\circ} \mathrm{C}$ and $5 \% \mathrm{CO}_{2}$. Utricles were adhered to Cell-Tak to maintain the flat architecture of the sensory epithelium and prevent the tissue from folding. To kill hair cells, $3 \mathrm{~mm}$ neomycin sulfate (Sigma-Aldrich) was added to the culture media for $24 \mathrm{~h}$ and then washed out with three rinses of media. For preliminary tests of other culture conditions that might affect the capacity for cells to differentiate into hair cells, we cultured limited numbers of utricles on Nucleopore filters (Laine et al., 2010) and cultured some utricles with $0 \%$ and $10 \%$ FBS.

Quantification of S-phase entry and hair cell numbers. In all applicable experiments, the number of BrdU- or EdU-labeled nuclei was manually counted using the Cell Counter plugin in ImageJ. EdU-positive/myosin VIIA-positive cells were counted separately. To quantify the amount of hair cell death in utricles from Atoh1-CreER ${ }^{\mathrm{TM}}$; ROSA $26^{\mathrm{DTA} /+}$ mice, the number of hair cells per $50 \mu \mathrm{m}^{2}$ was counted at nine different locations spaced along the anterior-posterior axis of the medial, striolar, and lateral regions of each utricle. The same procedure was used to quantify the percentage of eYFP-positive/myosin VIIA-positive hair cells in utricles from Atoh1-CreER ${ }^{\mathrm{TM}}$; ROSA26 $6^{\mathrm{eYFP} /+}$ mice.

Immunocytochemistry. Rabbit anti-myosin VIIA (1:200, Proteus BioSciences) was used to label hair cell somata, and rabbit anti-espin (1:10; generous gift from Dr. James Bartles, Northwestern University, Evanston, IL) was used to label stereocilia. Mouse anti-BrdU (1:50; BD Biosciences) was used to label cells that had incorporated BrdU during S-phase. Rabbit anti-GFP (1:200, Invitrogen) was used to label eYFP.

Vestibular organs were fixed in either fresh $4 \%$ paraformaldehyde in PBS for $1 \mathrm{~h}$ at room temperature (RT) or in Shandon Glyofixx (Thermo Scientific) overnight at $4^{\circ} \mathrm{C}$. After fixation, specimens were washed in PBS then preincubated for $1 \mathrm{~h}$ at RT in blocking solution, containing PBS and $0.2 \%$ Triton X-100 (PBS-T) as well as $10 \%$ NGS (Vector Laboratories). Samples to be labeled with anti-BrdU were incubated with DNase I ( $0.5 \mathrm{kunitz} / \mu \mathrm{l}$; Sigma) for $1 \mathrm{~h}$ at $37^{\circ} \mathrm{C}$ before adding the blocking solution. For detection of EdU, utricles were rinsed in PBS after the blocking step, and a copper-catalyzed Click-iT reaction kit was used per the manufacturer's instructions (Invitrogen). Samples were then incubated in the appropriate primary antibodies in PBS-T with $2 \%$ NGS overnight, fol- lowed by 3 rinses in PBS-T and incubation with Alexa-conjugated secondary antibodies (1:200, Invitrogen) and/or phalloidin $(5 \mathrm{U} / \mathrm{ml}$, Invitrogen) in PBS-T for $2 \mathrm{~h}$ at RT. Utricles were rinsed in PBS 3 times and mounted in SlowFade (Invitrogen). Specimens were imaged using Zeiss LSM 510 and LSM 700 confocal microscopes.

Statistics. For statistical comparisons, GraphPad Prism was used to conduct one-way or two-way ANOVAs followed by a Bonferroni's multiple-comparisons test ( $\alpha$ level $=0.05$ in all cases). All descriptive statistics are presented as mean \pm SEM.

\section{Results}

\section{Damage-induced proliferation declines postnatally in cultured mouse utricles}

It has remained unclear whether the limited hair cell regeneration capacity of vestibular organs in adult mammals is the result of an evolutionary loss of essential recovery processes that are found in non-mammals or results from the evolution of mammalian attributes that inhibit regeneration (Burns et al., 2008; Brigande and Heller, 2009). Here, we cultured utricles from P0, P2, P4, and P8 mice in BrdU-containing medium and killed hair cells using a $24 \mathrm{~h}$ treatment with $3 \mathrm{~mm}$ neomycin (Cunningham et al., 2002) to investigate the hypothesis that mitotic regeneration in adult mammals is restricted by derived characteristics that mammalian ears express during postnatal maturation. By $72 \mathrm{~h}$ after neomycin washout, the maculae of damaged $\mathrm{P} 0$ utricles contained 10-times more BrdU-positive nuclei than controls (192 \pm 19 vs $19 \pm 2 ; p<$ 0.05, Two-way ANOVA with Bonferroni's multiple-comparisons test; Fig. 1; $n=8$ ), but damage-induced proliferation declined quickly with age (Fig. $1 C ; n=8$ ). Also, no BrdU-positive/myosin VIIA-positive cells were detected in any of the samples, even when utricles were cultured for $21 \mathrm{~d}$. If hair cells had differentiated from the progeny produced from those damage-induced cell divisions, then BrdU-positive/myosin VIIA-positive cells should have formed. We suspected that the in vitro environment we were using provided insufficient support for hair cell differentiation, so we used mouse genetics to circumvent limitations of the culture environment and to directly investigate whether hair cells could be regenerated in vivo.

\section{Utricular hair cells can be reproducibly ablated in vivo using an inducible mouse model}

By crossing Atoh1-CreER ${ }^{\mathrm{TM}}$ mice with ROSA26 ${ }^{\mathrm{DTA} /+}$ mice, we generated offspring in which we could induce hair-cell-specific expression of DTA using the Atoh1 enhancer to drive CreER expression in hair cells (Chow et al., 2006; Weber et al., 2008). Cre-mediated excision of the stop sequence in the ROSA26-loxPstop-loxP-DTA (ROSA26 ${ }^{\text {DTA }}$ ) allele results in cell-autonomous ablation of Cre-positive cells (Ivanova et al., 2005; Abrahamsen et al., 2008). Utricles from Atoh1-CreER ${ }^{\mathrm{TM}}$; ROSA26 $6^{\mathrm{DTA} /+}$ mice, injected with tamoxifen once each at $\mathrm{P} 0$ and $\mathrm{P} 1$, exhibited significant, $19 \% \pm 4 \%, 41 \% \pm 6 \%$, and $48 \% \pm 4 \%$ decreases in hair cell density as measured at $\mathrm{P} 2, \mathrm{P} 5$, and $\mathrm{P} 11$, respectively $(p<$ 0.05; Two-way ANOVA with Bonferroni's multiple-comparisons test; Fig. $2 A, C ; n=4)$.

To determine whether the amount of hair cell loss we observed corresponded with the number of hair cells that exhibit Cre activity, we bred Atoh1-CreER ${ }^{\mathrm{TM}}$ mice with ROSA26 ${ }^{\mathrm{eYFP} /+}$ reporter mice and injected them with tamoxifen once a day on P0 and P1. In utricles fixed at P6, we found $50 \% \pm 5 \%$ of myosin VIIA-expressing hair cells also expressed eYFP (Fig. $2 B, C ; n=4$ ). This level of Cre activity is similar to the percentage decrease in hair cell number we observed in utricles from Atoh1-CreER ${ }^{\mathrm{TM}}$; ROSA $26^{\text {DTA/+ }}$ mice at P5 and P11, and slightly lower, but still consistent with the $60 \%$ recombination reported from Atoh1- 
CreER ${ }^{\mathrm{TM}} ; \mathrm{ROSA}_{26^{\mathrm{LacZ} /+}}$ mice, where Cre activity was assessed on P6 after tamoxifen injections at P0/P1 (Chow et al., 2006).

In utricles of Atoh1-CreER ${ }^{\mathrm{TM}}$; ROSA2 $6^{\mathrm{DTA} /+}$ mice that were fixed on P2, P5, or P10 following tamoxifen injections on $\mathrm{P} 0 / \mathrm{P} 1$, quantification showed that comparable decreases in the spatial density of myosin VIIA-positive hair cells occurred in the medial, striolar, and lateral regions (Fig. $2 C$, purple bars). The spatial density variations that resulted from DTAmediated hair cell loss at P5 and P10 resembled spatial variations in the incidence of eYFP-expressing hair cells observed in utricles of Atoh1-CreER ${ }^{\mathrm{TM}}$; ROSA26 $6^{\mathrm{eYFP} /+}$ reporter mice that were fixed at P6 after the same tamoxifen induction regimen (Fig. $2 C$, green bars).

We injected another group of Atoh1CreER $^{\mathrm{TM}}$; ROSA26 $6^{\mathrm{eYFP} /+}$ mice with tamoxifen once a day on P4 and P5 and found that $33 \% \pm 4 \%$ of their myosin VIIA-positive hair cells also expressed eYFP at P10 (Fig. 2E,F), which suggested that hair cells could be ablated at such older ages. When we gave Atoh1CreER ${ }^{\mathrm{TM}}$; ROSA26 ${ }^{\mathrm{DTA} /+}$ mice the same $\mathrm{P} 4 / \mathrm{P} 5$ tamoxifen induction regimen and fixed their utricles at P9 we observed a significant $29 \% \pm 5 \%$ decrease in utricular hair cell density compared with controls $(p<0.05$; Two-way ANOVA with Bonferroni's multiple-comparisons test; Fig. $2 D, F ; n=4)$. Thus, hair cells in the utricles of mice can be reproducibly ablated in vivo using inducible expression of DTA both early and late during the first postnatal week.

In all but one utricle from the Atoh1CreER ${ }^{\mathrm{TM}}$; ROSA26 $6^{\mathrm{eYFP} /+}$ mice that were induced with tamoxifen at $\mathrm{P} 0 / \mathrm{P} 1$ or $\mathrm{P} 4 / \mathrm{P} 5$, we detected $1-5$ eYFP-positive/myosin VIIA-negative cells that resembled supporting cells and extended down to the basal lamina. The intensity of eYFP in these cells appeared lower than eYFP in neighboring hair cells (data not shown). Since hair cells are being added to the sensory epithelium at these ages (Kirkegaard and Nyengaard, 2005), we suspect that the eYFP-expressing cells may be nascent hair cells in the earliest stages of differentiation. The presence of eYFP-positive/myosin VIIA-negative cells suggests that our method for inducing cell death may ablate some cells that are not fully differentiated hair cells. However, the low numbers of eYFP-positive/myosin VIIA-negative cells suggests that the effects of non-hair-cell-specific cell loss would be minimal compared with the effects of killing over a thousand differentiated, myosin VIIA-positive hair cells.

DTA-induced hair cell death evokes a significant proliferative response in the sensory epithelium of newborn mouse utricles To determine whether killing hair cells in the utricles of newborn Atoh1-CreER ${ }^{\mathrm{TM}}$; ROSA26 $6^{\mathrm{DTA} /+}$ mice would lead to a damageinduced proliferative response in vivo, we injected mice with tamoxifen at $\mathrm{P} 0$ and $\mathrm{P} 1$, and followed that treatment with a single
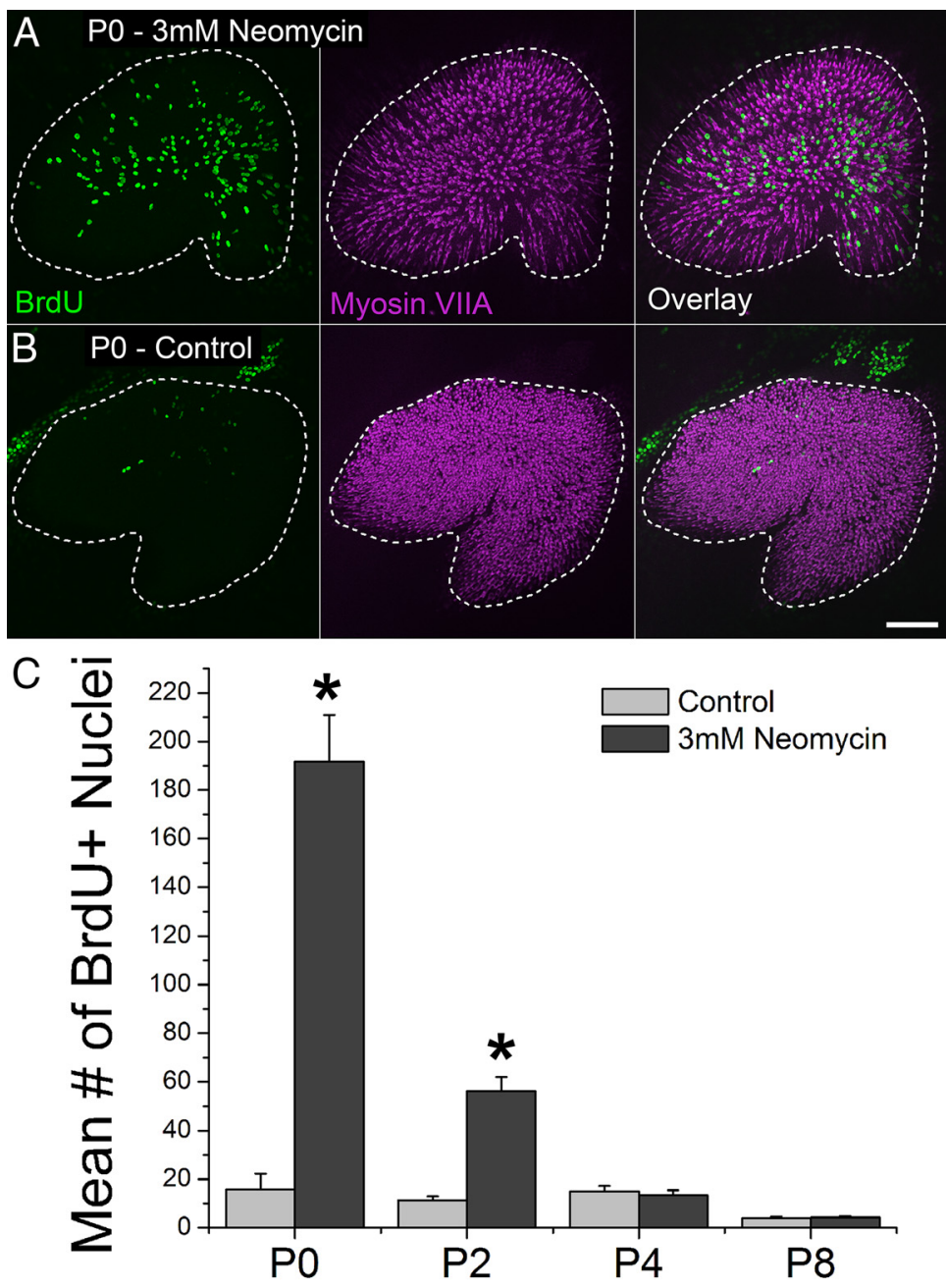

Figure 1. Cells in the utricles of newborn mice respond to hair cell death with robust proliferation in vitro. $A, B$, Confocal images of utricles from PO mice that were treated with $3 \mathrm{~mm}$ neomycin or vehicle control for $24 \mathrm{~h}$ and cultured for $72 \mathrm{~h}$ thereafter (BrdU, green, was included in the media throughout). Hair cells are labeled with an antibody to myosin VIIA (purple). A dashed line marks the macula's edge. Scale bar, $100 \mu \mathrm{m}$. C, Graph of BrdU-positive nuclei in the macula of neomycin-damaged and control utricles from mice of different ages, $n=8$ per age. Asterisks indicate a significant difference between treatment and controls $(p<0.05)$

injection of EdU given at either P2, P3, P4, or P8. Utricles from these mice were all fixed $24 \mathrm{~h}$ after the EdU injection and processed to reveal EdU and myosin VIIA labeling. Utricular maculae in mice that received EdU at P2, P3, and P4 exhibited 1.8-fold, 5.8-fold, and 10.3-fold more EdU-positive nuclei than littermate control mice lacking Cre or DTA $(p<0.05$, Two-way ANOVA with Bonferroni's multiple-comparisons test; Fig. $3 ; n=4)$. Since cell proliferation ceases by $\mathrm{P} 2$ in the undamaged mouse utricular sensory epithelia, as shown by the data in Ruben's (1967) investigation of terminal mitoses, the significant increases in proliferation that occurred here in Atoh1-CreER ${ }^{\mathrm{TM}}$; ROSA2 $6^{\mathrm{DTA} /+}$ mice, which were up to $4 \mathrm{~d}$ old, appear to be responses evoked by hair cell death. However, EdU labeling did not differ significantly between the groups of experimental and control mice that received EdU at P8 ( $p=0.2426$, Two-way ANOVA with Bonferroni's multiple-comparisons test; Fig. $3 C$; $n=4$ ), leading to the conclusion that the damage-induced proliferative responses subsided 4-8 d after hair cell death was induced through the tamoxifenmediated expression of DTA on P0/P1.

To determine whether a proliferative response could be extended later in life by inducing the death of hair cells at an older age, we gave mice tamoxifen injections at P4/P5 and a single EdU 

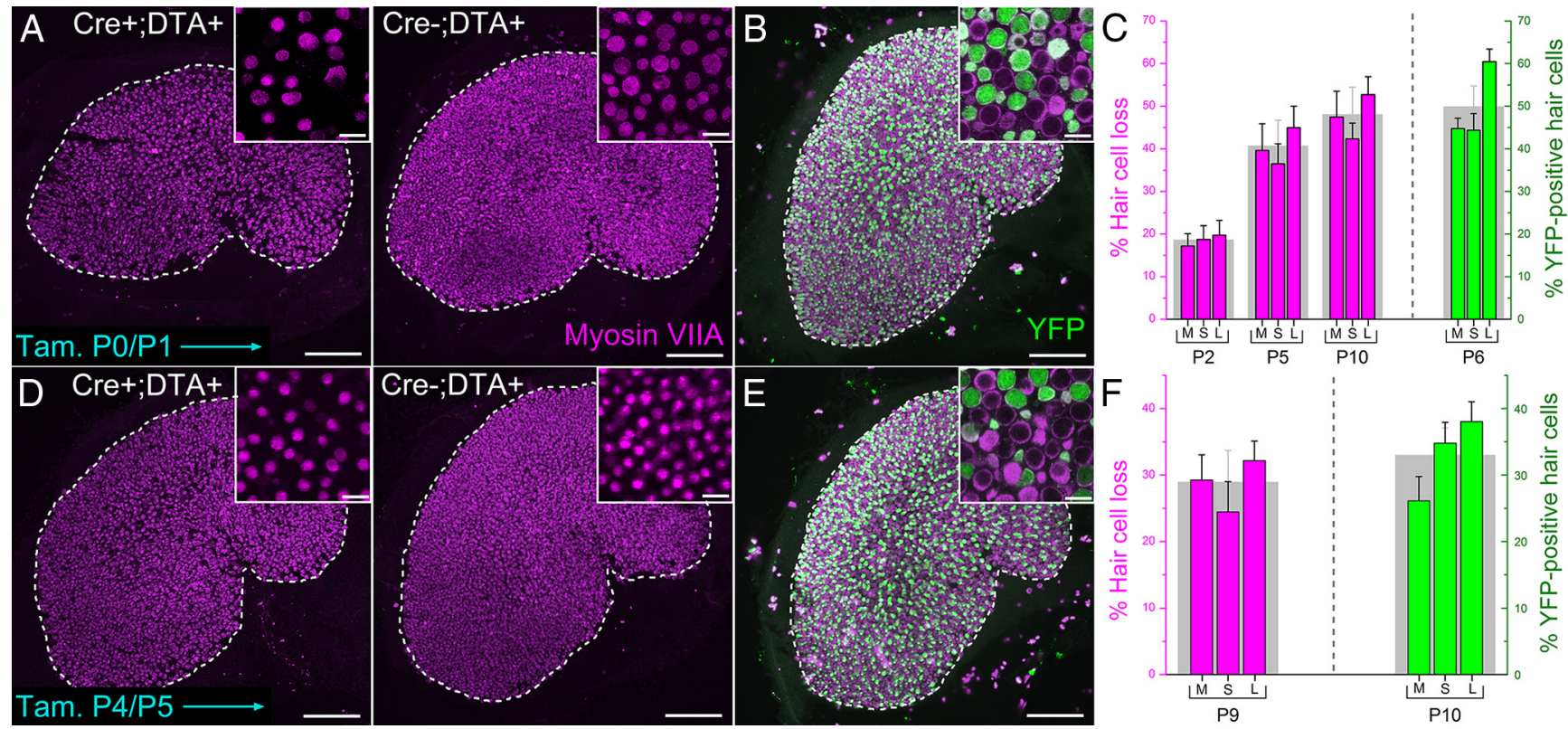

Figure 2. Hair cells in neonates can be ablated in vivo using an inducible mouse model. A, Confocal images of utricles from an Atoh1-CreERTM; ROSA26 ${ }^{\text {DTA/+ }}$ mouse and a ROSA26 ${ }^{\text {DTA/+ }}$ control mouse injected with tamoxifen at P0 and P1 and killed at P10. Hair cells are labeled with antibodies to myosin VIIA (purple). Scale bar, $100 \mu \mathrm{m}$. Insets show zoomed regions of the sensory epithelium. Scale bar, $10 \mu \mathrm{m}$. B. Confocal image of a utricle from an Atoh1-CreERTM; ROSA26 ${ }^{\text {YYFP/+ }}$ mouse induced with tamoxifen at P0/P1 and killed at P6. eYFP is shown in green. Scale bar, $100 \mu \mathrm{m}$. Inset shows zoomed region of the sensory epithelium. Scale bar, $10 \mu \mathrm{m}$. C, Graph of the percentage difference in the density of hair cells between utricles from Atoh1-CreERTM; ROSA26 ${ }^{\text {DTA } /+}$ mice and control mice that were induced with tamoxifen at PO/P1 and killed at the ages indicated (bars in purple), $n=4 . \mathrm{M}$, medial; $S$, striolar; L, lateral regions of the utricle, respectively. The gray bar behind the colored columns shows the average for the entire utricle. Also shown is the percentage of eYFP-positive hair cells in utricles from Atoh1-CreERTM; ROSA26 $6^{\text {eYFP/+ }}$ mice induced with tamoxifen at $P 0 / P 1$ and killed at $\mathrm{P} 6$ (bars in green), $n=4$. Data expressed as mean \pm SEM. $\boldsymbol{D}-\boldsymbol{F}$, Same as in $\boldsymbol{A}-\boldsymbol{C}$, except that mice were induced with tamoxifen at $\mathrm{P} 4 / \mathrm{P} 5$. Utricles in $\boldsymbol{D}$ and $\boldsymbol{E}$ were fixed from mice killed at $\mathrm{P} 9$ and $\mathrm{P} 10$, respectively. Data represented by green bars in F were taken from utricles fixed at P10. Note different scales for graphs in $\boldsymbol{C}$ and $\boldsymbol{F}$.

injection at P6, P7, or P8. In utricles fixed $24 \mathrm{~h}$ after the injection of EdU, the mean number of EdU-positive cells detected in the utricular maculae of the Atoh1-CreER ${ }^{\mathrm{TM}}$; ROSA26 $6^{\mathrm{DTA} /+}$ mice $(\mathrm{P} 7=2 \pm 1, \mathrm{P} 8=5 \pm 2$, and $\mathrm{P} 9=5 \pm 2)$ and the maculae from the littermate controls lacking Cre or DTA ( $\mathrm{P} 7=3 \pm 1, \mathrm{P} 8=2 \pm$ 1 , and $\mathrm{P} 9=3 \pm 1$ ) was low at all ages, and sample differences between the DTA mouse model and controls did not reach significance ( $p=0.3319$, Two-way ANOVA; $n=3-4)$. Thus, the proliferation that is evoked by hair cell damage in mouse utricles in vivo declines with postnatal age along an age-related time course that is similar to progressive declines in supporting cell proliferation that have been measured in vitro (Gu et al., 1997, 2007; Hume et al., 2003; Davies et al., 2007; Meyers and Corwin, 2007; Burns et al., 2008; Lu and Corwin, 2008).

\section{Mitotic hair cell regeneration occurs in newborn mouse utricles in vivo}

In utricles from the P0/P1 tamoxifen-induced Atoh1-CreER ${ }^{\mathrm{TM}}$; ROSA2 $6^{\mathrm{DTA} /+}$ mice that were fixed between $\mathrm{P} 3$ and $\mathrm{P} 9$, just $24 \mathrm{~h}$ after they had each received an injection of EdU, none of the EdU-positive cells had become myosin VIIA-positive hair cells. However, utricles from other groups of P0/P1 tamoxifeninduced Atoh1-CreER ${ }^{\mathrm{TM}}$; ROSA26 $6^{\mathrm{DTA} /+}$ mice that each received a single EdU injection on P4 and were fixed at either P10 or P15 contained substantial fractions of EdU-positive cells that were positive for myosin VIIA (P10 $=23 \% \pm 0.8 \%, \mathrm{P} 15=22 \% \pm 2 \%$; Fig. $4 C-F)$. The somata of these cells had shapes characteristic of hair cells, and hair bundles that labeled with an antibody to espin protruding from their apical surfaces (Fig. 4C-E). Many of these EdU-positive hair cells appeared in close proximity to a myosin VIIA-negative cell that contained an EdU-positive nucleus located in the basal nuclear layer that is comprised of supporting cell nuclei (Fig. 4D, E, arrowheads). In contrast, no EdU-positive/ myosin VIIA-positive cells were detected in utricles from littermate Cre-negative or DTA-negative control mice that were fixed on P10 or P15 after receiving EdU on P4. These results reveal that the vestibular organs of neonatal mice must contain all the elements necessary for responding to hair cell loss with cell proliferation that leads to mitotic hair cell regeneration in vivo.

\section{Discussion}

\section{A transient regenerative potential in murine balance organs}

In showing that newborn mice are capable of significant mitotic regeneration of vestibular hair cells in vivo, these results challenge the notion that mammals lack molecular circuitry that is essential to mitotic hair cell regeneration and expressed only in nonmammalian ears. Our results also show that changes in the regenerative capabilities of the vestibular sensory epithelia occur early in the postnatal maturation of rodents, since hair cell death induced by giving tamoxifen to 5-d-old Atoh1-CreER ${ }^{\mathrm{TM}}$; ROSA2 $6^{\mathrm{DTA} /+}$ mice resulted in only low numbers of EdUpositive utricular cells, while utricles of mice that were given tamoxifen at P0/P1, followed by a single injection of EdU at P4, and fixation on the next day, contained nearly twice as many proliferating cells as had been reported previously after days to weeks of continuous BrdU labeling of ototoxin-damaged vestibular organs in adult rodents (Tanyeri et al., 1995; Li and Forge, 1997; Kuntz and Oesterle, 1998; Ogata et al., 1999; Oesterle et al., 2003; Kawamoto et al., 2009). While our data fail to add support for the notion that mammalian ears lack essential molecular circuits found in non-mammalian ears, it remains unclear exactly how maturational changes inhibit, disable, or shut down in vivo hair cell regeneration in young mammals. 

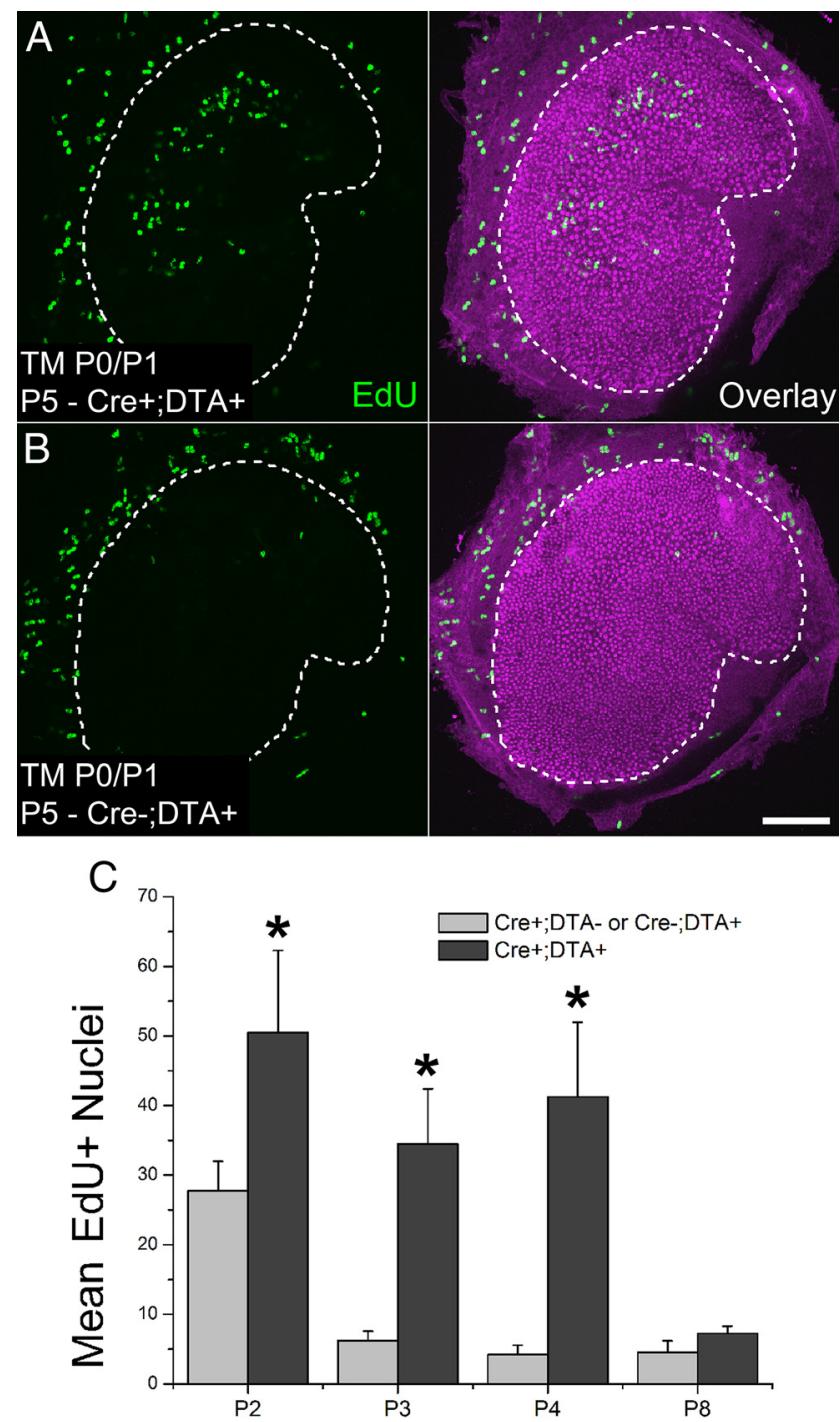

Age of EdU Injection (Harvest 24 hrs later)

Figure 3. Cells in the utricles of newborn mice respond to hair cell death with robust proliferation in vivo. $A, B$, Confocal images of utricles from an Atoh1-CreER ${ }^{\mathrm{TM}}$; ROSA26 ${ }^{\mathrm{DTA} /+}$ mouse and a ROSA26 $6^{\mathrm{DTA} /+}$ control mouse induced with tamoxifen (TM) at P0/P1. EdU (green) was injected once at $\mathrm{P} 4$ and utricles were harvested $24 \mathrm{~h}$ later. Hair cells are labeled with an antibody to myosin VIIA (purple). Scale bar, $100 \mu \mathrm{m}$. C, Graph of the number of EdU-positive nuclei in maculae of Atoh1-CreERTM; ROSA26 ${ }^{\text {DTA/+ }}$ or control mice of different ages that were induced with tamoxifen at $\mathrm{P} 0 / \mathrm{P} 1$ and received EdU $24 \mathrm{~h}$ before utricle fixation, $n=4$ per age. Data expressed as mean \pm SEM. Asterisks indicate significant difference between treatment and controls $(p<0.05)$.

\section{What drives the neonatal decline in mitotic regeneration?}

The age-related declines in the early and robust proliferation responses observed here in neomycin-treated utricle cultures and in vivo are reminiscent of responses observed in vestibular epithelia that were delaminated from rodent utricles and cultured with Glial Growth Factor 2 (rhGGF2), insulin, or serum. Over $40 \%$ of the cells entered S-phase in $72 \mathrm{~h}$ when such epithelia were cultured from newborn rodents, but little or no labeling occurred in $72 \mathrm{~h}$ in such epithelia from 2- and 3-week-old rodents. However, when adult epithelia were allowed to spread by culturing for 1 week or longer, proliferation increased 20 -fold with rhGGF2 over control cultures, even though the overall incidence of proliferating cells remained low (Gu et al., 1996, 1997, 2007; Mont- couquiol and Corwin, 2001a,b; Davies et al., 2007; Lu and Corwin, 2008).

Since rhGGF2 and insulin signal through different receptors and intracellular pathways, and since rhGGF2 is a ligand for ErbB receptors that appear to be expressed continuously, the decline in proliferative response does not appear to be due to receptor downregulation (Zheng et al., 1999; Hume et al., 2003; Gu et al., 2007). Instead, the decline in proliferative response mirrors an age-related decline in the propensity for rodent supporting cells to change from columnar to spread shapes both in cultured sheets and vestibular epithelia healing in situ (Davies et al., 2007; Meyers and Corwin, 2007). Contrasting with this, supporting cells in utricular epithelia from adult birds continue to exhibit rapid spreading and high rates of proliferation that are undiminished from those of hatchlings (Burns et al., 2008; Collado et al., 2011a).

For both humans and mice, the decrease in spreading could stem from postnatal thickening of F-actin belts that bracket the apical junctions between neighboring vestibular supporting cells (Meyers and Corwin, 2007; Burns et al., 2008). In mice, those belts grow 13 -fold thicker and come to occupy $89 \%$ of the adult supporting cell's area at the level of the adherens junction. There is also a strong inverse correlation $(r=-0.98)$ between the belt thickening that appears unique to these cells and proliferative responses that occur in damaged murine balance epithelia at different postnatal ages. In contrast, corresponding perijunctional F-actin belts in the supporting cells of chicken utricles, which exhibit lifelong regeneration of hair cells, remain thin even in adulthood (Burns et al., 2008).

Differences between mammals and the birds, sharks, bony fish, and amphibians that all exhibit rapid mitotic hair cell regeneration also extend to the cadherins at intercellular junctions of supporting cells (Hackett et al., 2002; Warchol, 2007; Burns et al., 2008; Collado et al., 2011b; J. Burns, E. Oliver, and J.T. Corwin, unpublished observations). Chicken vestibular epithelia express little or no E-cadherin, while vestibular supporting cells in mammals express E-cadherin strongly, and at levels that increase sixfold during postnatal maturation. Such correlations led to the hypothesis that the postnatal development of the junctional specializations of mammalian supporting cells contributes to the striking differences between the hair cell regeneration capacities of mammals and non-mammals, and to the development of postnatal limits to the regeneration responses that occur in mammalian ears, but the potential for causality and a defined mechanism remain to be explored (Burns et al., 2008).

Cell cycle regulatory proteins that are expressed in many tissues, such as the retinoblastoma protein $(\mathrm{pRb})$ and the cyclindependent kinase inhibitors, p2 $7^{\text {Kipl }}$, p21 ${ }^{\text {Cipl } 1}$, and p19 ${ }^{\text {INK4d }}$, have established influences on the proliferation and postmitotic state of cells during the embryonic development of the mammalian cochlea, so it seems likely that such proteins may have roles in limiting vestibular regeneration (Chen and Segil, 1999; Löwenheim et al., 1999; Mantela et al., 2005; Sage et al., 2005; Weber et al., 2008; Groves, 2010; Laine et al., 2010; Yu et al., 2010; Huang et al., 2011). Although murine vestibular epithelia exhibit weak expression of $\mathrm{p} 27^{\mathrm{Kip} 1}$, cyclin D1 is expressed in numerous vestibular supporting cell nuclei in neonatal mice and in considerably fewer cells within the vestibular epithelia of older mice (Laine et al., 2010).

Recently, when Loponen et al. (2011) used an adenovirus vector to overexpress cyclin D1 in supporting cells of utricles cultured from adult (P50) mice to test whether its decreased expression limits proliferation in adults, they observed that a 

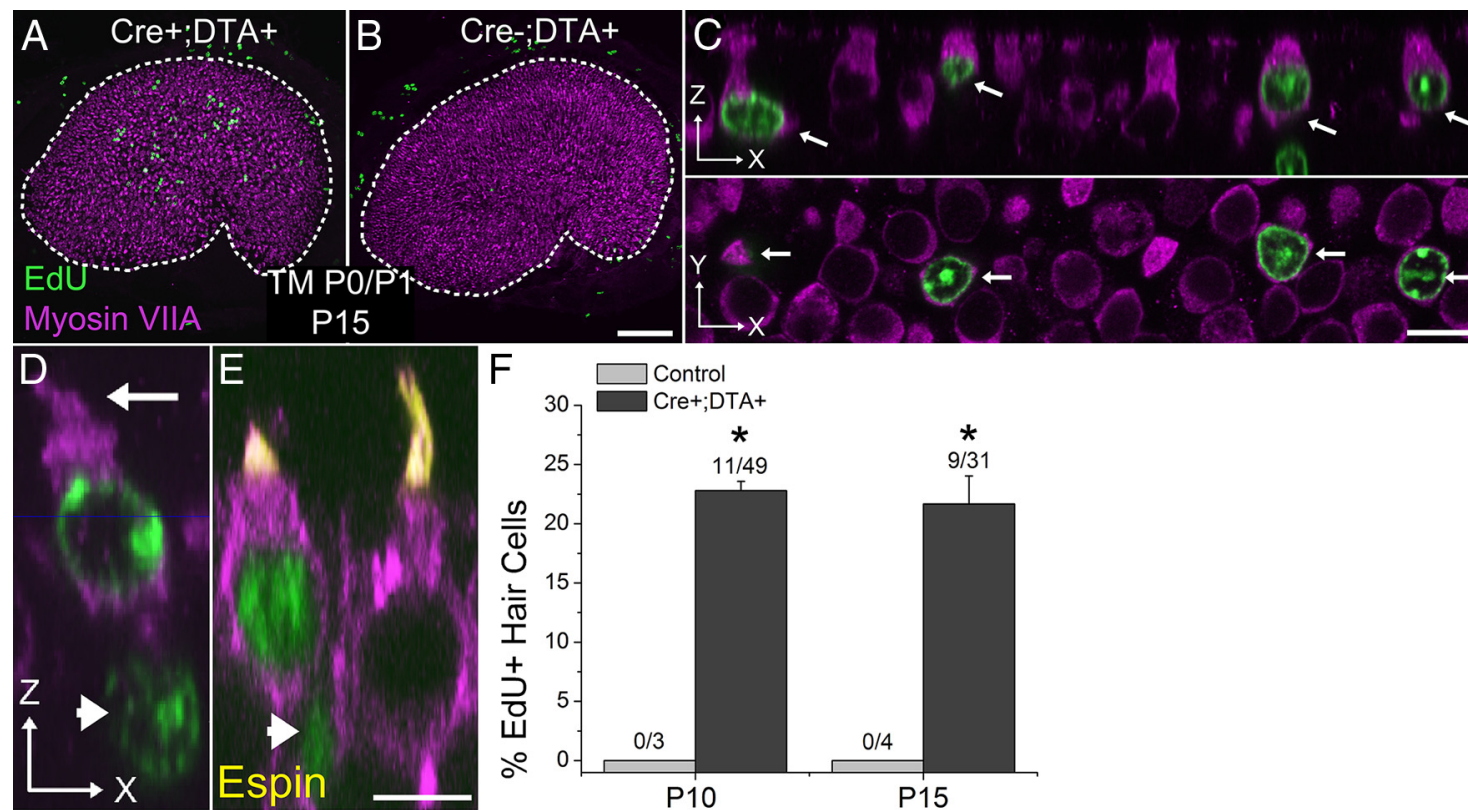

Figure 4. Damage-induced proliferation gives rise to new hair cells in vivo. $A, B$, Confocal image of a utricle from a P15 Atoh1-CreERTM; ROSA26 ${ }^{\text {DTA/+ }}$ mouse and a control mouse lacking Cre that received tamoxifen (TM) at P0/P1 and EdU (green) at P4. Hair cells are labeled with an antibody to myosin VIIA (purple). Scale bar, $100 \mu \mathrm{m}$. C, Confocal images of a zoomed region in $A$. Top ( $x$-z view), Orthogonal view along the long axis of the hair cells. Arrows indicate four EdU-positive/myosin VIIA-positive hair cells. Bottom ( $x$-y view), Cross-sectional view taken at the level of the hair cell nuclei. Scale bar, $10 \mu \mathrm{m} . \boldsymbol{D}, \boldsymbol{E}$, High-resolution confocal images of regenerated hair cells in utricles from P15 Atoh1-CreERTM; ROSA26 ${ }^{\text {TTA/+ }}$ mice that received tamoxifen at P0/P1 and EdU at P4. Image is parallel to the long axis of the hair cells ( $x$-z view). Arrow marks a hair bundle, and arrowheads markEdU-positive hair cell/supporting cell pairs. Regenerated hair cells have shorter hair bundles than preexisting hair cells, as shown by labeling with an espin antibody (D). Scale bar, $10 \mu \mathrm{m}$. $\boldsymbol{F}$, Graph of the percentage of EdU-positive cells that were also positive for myosin VIIA in utricles from P10 and P15 Atoh1-CreERTM; ROSA26 ${ }^{\text {DTA } /+}$ or control mice that were injected once with EdU at P4 (tamoxifen given at PO/P1), $n=4$. In the fractions above the bars, the mean number of EdU-positive/myosin VIIA-positive cells is shown in the numerator, and the mean number of EdU-positive cells is shown in the denominator. Data in graphs are expressed as mean \pm SEM. Asterisks indicate significant difference between treatment and controls $(p<0.05)$.

large percentage of the transduced supporting cells passed through the $\mathrm{G}_{1}-\mathrm{S}$ restriction point, as shown by BrdU incorporation and Ki-67 immunostaining. However, the number of cells that progressed from $\mathrm{S}$-phase to mitosis was equivalent to just $0.6 \%$ of the Ki-67+ cells. To explore age dependence, they overexpressed cyclin D1 in utricles cultured from P9 neonates, finding a slight, but still significant increase (to $2.5 \%$ of the amount of $\mathrm{Ki}-67+$ cells) in the cells that progressed through mitosis. Such results are consistent with the potential existence of an intrinsic barrier to cell cycle progression (Loponen et al., 2011). The apparent age dependence of such a barrier also is consistent with the sharp in vivo decline in proliferation observed here in the DTA mouse model when tamoxifen injections were given at P4/P5. Postnatal reinforcement of intercellular junctions and cytoskeletons of mammalian supporting cells might contribute to such an intrinsic barrier by restricting dedifferentiation and cell cycle progression (Burns et al., 2008), but it remains to be determined whether those cytological changes have such effects.

\section{What cells give rise to the regenerated hair cells in mice?}

During the proliferative regeneration observed here in mice and the well established regeneration that occurs in non-mammals, resident cells divide and produce progeny that can become hair cells and supporting cells, but it is yet to be established whether those progeny arise from undifferentiated reserve stem cells or from more mature supporting cells that dedifferentiate and become multipotent progenitors. Both may occur and are consistent with results obtained when murine vestibular organs are dissociated and placed in suspension culture. Such cultures contain yet-to-be-identified stem cells that can be serially passaged and expanded before giving rise to hair cells, and in addition, endodermal and mesodermal cell types (Li et al., 2003; Oshima et al., 2007). Similar to the observations from more intact cultures of vestibular epithelia, the yields of dissociation-derived stem cells decrease with increasing rodent age, but it is not yet known whether the decrease occurs through the gradual death or because of the differentiation of cells within the stem cell pool (Ronaghi et al., 2012).

The results obtained in cultures here contrast with the mitotic replacement of hair cells that occurs when vestibular organs from frogs and chickens are treated with aminoglycoside antibiotics and maintained in culture (Baird et al., 1996; Matsui et al., 2000). BrdU labeled 100-200 or more cells in the sensory epithelium of each newborn mouse utricle that we cultured after neomycin killed hair cells, but the progeny of those cells did not differentiate into hair cells under the various conditions we tested. Yet, it seems likely that conditions conducive to hair cell differentiation could be identified through parametric testing, since methods have been described for guiding the progeny of murine embryonic stem cells and induced pluripotent cells to differentiate as hair cells (Oshima et al., 2010).

The results here are consistent with the hypothesis that rapid neonatal maturation of uniquely specialized intercellular junctions contributes to restricting the plasticity that immature mammalian supporting cells appear to exhibit, since those junctions change markedly between P0 and P4 (Burns et al., 2008; Collado et al., 2011a); but causality has not been established. This and alternative hypotheses now may be more readily tested, since the findings here show that when preexisting hair cells are killed at an early stage of neonatal life, mice can mitotically regenerate significant numbers of hair cells in vivo. Results here also highlight the potential usefulness of the DTA mouse model for investigating 
how limits to regeneration in more mature mammalian ears eventually may be overcome.

\section{References}

Abrahamsen B, Zhao J, Asante CO, Cendan CM, Marsh S, Martinez-Barbera JP, Nassar MA, Dickenson AH, Wood JN (2008) The cell and molecular basis of mechanical, cold, and inflammatory pain. Science 321:702-705.

Baird RA, Steyger PS, Schuff NR (1996) Mitotic and nonmitotic hair cell regeneration in the bullfrog vestibular otolith organs. Ann N Y Acad Sci 781:59-70.

Brigande JV, Heller S (2009) Quo vadis, hair cell regeneration? Nat Neurosci 12:679-685.

Burns JC, Christophel JJ, Collado MS, Magnus C, Carfrae M, Corwin JT (2008) Reinforcement of cell junctions correlates with the absence of hair cell regeneration in mammals and its occurrence in birds. J Comp Neurol 511:396-414.

Chen P, Segil N (1999) p27(Kip1) links cell proliferation to morphogenesis in the developing organ of Corti. Development 126:1581-1590.

Chow LM, Tian Y, Weber T, Corbett M, Zuo J, Baker SJ (2006) Inducible Cre recombinase activity in mouse cerebellar granule cell precursors and inner ear hair cells. Dev Dyn 235:2991-2998.

Collado MS, Burns JC, Meyers JR, Corwin JT (2011a) Variations in shapesensitive restriction points mirror differences in the regeneration capacities of avian and mammalian ears. PloS One 6:e23861.

Collado MS, Thiede BR, Baker W, Askew C, Igbani LM, Corwin JT (2011b) The postnatal accumulation of junctional E-cadherin is inversely correlated with the capacity for supporting cells to convert directly into sensory hair cells in mammalian balance organs. J Neurosci 31:11855-11866.

Corwin JT (1981) Postembryonic production and aging of inner ear hair cells in sharks. J Comp Neurol 201:541-553.

Corwin JT (1985) Perpetual production of hair cells and maturational changes in hair cell ultrastructure accompany postembryonic growth in an amphibian ear. Proc Natl Acad Sci U S A 82:3911-3915.

Corwin JT (1986) Regeneration and self-repair in hair cell epithelia: experimental evaluation of capacities and limitations. In: Biology of change in otolaryngology (Ruben RJ, Van de Water TR, Rubel EW, eds), pp 291304. New York: Elsevier.

Corwin JT, Cotanche DA (1988) Regeneration of sensory hair cells after acoustic trauma. Science 240:1772-1774

Cunningham LL, Cheng AG, Rubel EW (2002) Caspase activation in hair cells of the mouse utricle exposed to neomycin. J Neurosci 22:8532-8540.

Davies D, Magnus C, Corwin JT (2007) Developmental changes in cellextracellular matrix interactions limit proliferation in the mammalian inner ear. Eur J Neurosci 25:985-998.

Forge A, Li L, Corwin JT, Nevill G (1993) Ultrastructural evidence for hair cell regeneration in the mammalian inner ear. Science 259:1616-1619.

Forge A, Li L, Nevill G (1998) Hair cell recovery in the vestibular sensory epithelia of mature guinea pigs. J Comp Neurol 397:69-88.

Groves AK (2010) The challenge of hair cell regeneration. Exp Biol Med (Maywood) 235:434-446.

Gu R, Marchionni M, Corwin JT (1996) Glial growth factor enhances supporting cell proliferation in rodent vestibular epithelia cultured in isolation. Soc Neurosci Abstr 21:520.

Gu R, Marchionni M, Corwin JT (1997) Age-related decreases in proliferation within isolated mammalian vestibular epithelia cultured in control and glial growth factor 2 medium. Assoc Res Otolaryngol Abstr 20:390.

Gu R, Montcouquiol M, Marchionni M, Corwin JT (2007) Proliferative responses to growth factors decline rapidly during postnatal maturation of mammalian hair cell epithelia. Eur J Neurosci 25:1363-1372.

Hackett L, Davies D, Helyer R, Kennedy H, Kros C, Lawlor P, Rivolta MN, Holley M (2002) E-cadherin and the differentiation of mammalian vestibular hair cells. Exp Cell Res 278:19-30.

Huang M, Sage C, Tang Y, Lee SG, Petrillo M, Hinds PW, Chen ZY (2011) Overlapping and distinct $\mathrm{pRb}$ pathways in the mammalian auditory and vestibular organs. Cell Cycle 10:337-351.

Hume CR, Kirkegaard M, Oesterle EC (2003) ErbB expression: the mouse inner ear and maturation of the mitogenic response to heregulin. J Assoc Res Otolaryngol 4:422-443.

Ivanova A, Signore M, Caro N, Greene ND, Copp AJ, Martinez-Barbera JP (2005) In vivo genetic ablation by Cre-mediated expression of diphtheria toxin fragment A. Genesis 43:129-135.

Jorgensen JM, Mathiesen C (1988) The avian inner ear. Continuous pro- duction of hair cells in vestibular sensory organs, but not in the auditory papilla. Naturwissenschaften 75:319-320.

Kawamoto K, Izumikawa M, Beyer LA, Atkin GM, Raphael Y (2009) Spontaneous hair cell regeneration in the mouse utricle following gentamicin ototoxicity. Hear Res 247:17-26.

Kirkegaard M, Nyengaard JR (2005) Stereological study of postnatal development in the mouse utricular macula. J Comp Neurol 492:132-144.

Kuntz AL, Oesterle EC (1998) Transforming growth factor alpha with insulin stimulates cell proliferation in vivo in adult rat vestibular sensory epithelium. J Comp Neurol 399:413-423.

Laine H, Sulg M, Kirjavainen A, Pirvola U (2010) Cell cycle regulation in the inner ear sensory epithelia: role of cyclin D1 and cyclin-dependent kinase inhibitors. Dev Biol 337:134-146.

Lanford PJ, Presson JC, Popper AN (1996) Cell proliferation and hair cell addition in the ear of the goldfish, Carassius auratus. Hear Res 100:1-9.

Li H, Liu H, Heller S (2003) Pluripotent stem cells from the adult mouse inner ear. Nat Med 9:1293-1299.

Li L, Forge A (1997) Morphological evidence for supporting cell to hair cell conversion in the mammalian utricular macula. Int J Dev Neurosci $15: 433-446$.

Li L, Nevill G, Forge A (1995) Two modes of hair cell loss from the vestibular sensory epithelia of the guinea pig inner ear. J Comp Neurol 355:405-417.

Lin V, Golub JS, Nguyen TB, Hume CR, Oesterle EC, Stone JS (2011) Inhibition of notch activity promotes nonmitotic regeneration of hair cells in the adult mouse utricles. J Neurosci 31:15329-15339.

Loponen H, Ylikoski J, Albrecht JH, Pirvola U (2011) Restrictions in cell cycle progression of adult vestibular supporting cells in response to ectopic cyclin d 1 expression. PloS One 6:e27360.

Löwenheim H, Furness DN, Kil J, Zinn C, Gültig K, Fero ML, Frost D, Gummer AW, Roberts JM, Rubel EW, Hackney CM, Zenner HP (1999) Gene disruption of $\mathrm{p} 27(\mathrm{Kip} 1)$ allows cell proliferation in the postnatal and adult organ of Corti. Proc Natl Acad Sci U S A 96:4084-4088.

Lu Z, Corwin JT (2008) The influence of glycogen synthase kinase 3 in limiting cell addition in the mammalian ear. Dev Neurobiol 68:1059-1075.

Mantela J, Jiang Z, Ylikoski J, Fritzsch B, Zacksenhaus E, Pirvola U (2005) The retinoblastoma gene pathway regulates the postmitotic state of hair cells of the mouse inner ear. Development 132:2377-2388.

Matsui JI, Oesterle EC, Stone JS, Rubel EW (2000) Characterization of damage and regeneration in cultured avian utricles. J Assoc Res Otolaryngol $1: 46-63$.

Meyers JR, Corwin JT (2007) Shape change controls supporting cell proliferation in lesioned mammalian balance epithelium. J Neurosci $27: 4313-4325$.

Montcouquiol M, Corwin JT (2001a) Intracellular signals that control cell proliferation in mammalian balance epithelia: key roles for phosphatidylinositol-3 kinase, mammalian target of rapamycin, and S6 kinases in preference to calcium, protein kinase $C$, and mitogenactivated protein kinase. J Neurosci 21:570-580.

Montcouquiol M, Corwin JT (2001b) Brief treatments with forskolin enhance s-phase entry in balance epithelia from the ears of rats. J Neurosci 21:974-982.

Oesterle EC, Cunningham DE, Westrum LE, Rubel EW (2003) Ultrastructural analysis of $\left[{ }^{3} \mathrm{H}\right]$ thymidine-labeled cells in the rat utricular macula. J Comp Neurol 463:177-195.

Ogata Y, Slepecky NB, Takahashi M (1999) Study of the gerbil utricular macula following treatment with gentamicin, by use of bromodeoxyuridine and calmodulin immunohistochemical labelling. Hear Res 133:53-60.

Oshima K, Grimm CM, Corrales CE, Senn P, Martinez Monedero R, Géléoc GS, Edge A, Holt JR, Heller S (2007) Differential distribution of stem cells in the auditory and vestibular organs of the inner ear. J Assoc Res Otolaryngol 8:18-31.

Oshima K, Shin K, Diensthuber M, Peng AW, Ricci AJ, Heller S (2010) Mechanosensitive hair cell-like cells from embryonic and induced pluripotent stem cells. Cell 141:704-716.

Popper AN, Hoxter B (1990) Growth of a fish ear. II. Locations of newly proliferated sensory hair cells in the saccular epithelium of Astronotus ocellatus. Hear Res 45:33-40.

Ronaghi M, Nasr M, Heller S (2012) Inner ear stem cells—an oxymoron, but why? Stem Cells 30:69-74.

Ruben RJ (1967) Development of the inner ear of the mouse: a radioautographic study of terminal mitoses. Acta Otolaryngol Suppl 220:1-44. 
Ryals BM, Rubel EW (1988) Hair cell regeneration after acoustic trauma in adult Coturnix quail. Science 240:1774-1776.

Sage C, Huang M, Karimi K, Gutierrez G, Vollrath MA, Zhang DS, GarcíaAñoveros J, Hinds PW, Corwin JT, Corey DP, Chen ZY (2005) Proliferation of functional hair cells in vivo in the absence of the retinoblastoma protein. Science 307:1114-1118.

Stone JS, Cotanche DA (2007) Hair cell regeneration in the avian auditory epithelium. Int J Dev Biol 51:633-647.

Tanyeri H, Lopez I, Honrubia V (1995) Histological evidence for hair cell regeneration after ototoxic cell destruction with local application of gentamicin in the chinchilla crista ampullaris. Hear Res 89:194-202.

Warchol ME (2007) Characterization of supporting cell phenotype in the avian inner ear: implications for sensory regeneration. Hear Res 227:11-18.

Warchol ME (2011) Sensory regeneration in the vertebrate inner ear: differences at the levels of cells and species. Hear Res 273:72-79.
Warchol ME, Lambert PR, Goldstein BJ, Forge A, Corwin JT (1993) Regenerative proliferation in inner ear sensory epithelia from adult guinea pigs and humans. Science 259:1619-1622.

Weber T, Corbett MK, Chow LM, Valentine MB, Baker SJ, Zuo J (2008) Rapid cell-cycle reentry and cell death after acute inactivation of the retinoblastoma gene product in postnatal cochlear hair cells. Proc Natl Acad Sci U S A 105:781-785.

Yu Y, Weber T, Yamashita T, Liu Z, Valentine MB, Cox BC, Zuo J (2010) In vivo proliferation of postmitotic cochlear supporting cells by acute ablation of the retinoblastoma protein in neonatal mice. J Neurosci 30:5927-5936.

Zheng JL, Frantz G, Lewis AK, Sliwkowski M, Gao WQ (1999) Heregulin enhances regenerative proliferation in postnatal rat utricular sensory epithelium after ototoxic damage. J Neurocytol 28:901-912.

Zupanc GK (2008) Adult neurogenesis and neuronal regeneration in the brain of teleost fish. J Physiol Paris 102:357-373. 